\title{
New Method for the Development of Plasmonic Metal-Semiconductor Interface Layer: Polymer Composites with Reduced Energy Band Gap
}

\author{
Shujahadeen B. Aziz, ${ }^{1,2}$ Soran M. Mamand, ${ }^{1}$ Salah R. Saed, ${ }^{3}$ \\ Ranjdar M. Abdullah, ${ }^{1}$ and Sarkawt A. Hussein ${ }^{1}$ \\ ${ }^{1}$ Advanced Polymeric Materials Research Lab., Department of Physics, College of Science, University of Sulaimani, \\ Qlyasan Street, Sulaimani, Kurdistan Region, Iraq \\ ${ }^{2}$ Komar Research Center (KRC), Komar University of Science and Technology, Sulaimani, Kurdistan Region 46001, Iraq \\ ${ }^{3}$ Charmo Research Center, Charmo University, Peshawa Street, Chamchamal, Sulaimani, Kurdistan Region, Iraq
}

Correspondence should be addressed to Shujahadeen B. Aziz; shujaadeen78@yahoo.com

Received 24 August 2017; Accepted 1 November 2017; Published 7 December 2017

Academic Editor: Xuping Sun

Copyright (C) 2017 Shujahadeen B. Aziz et al. This is an open access article distributed under the Creative Commons Attribution License, which permits unrestricted use, distribution, and reproduction in any medium, provided the original work is properly cited.

\begin{abstract}
Silver nanoparticles within a host polymer of chitosan were synthesized by using in situ method. Ultraviolet-visible spectroscopy was then carried out for the prepared chitosan : silver triflate (CS : AgTf) samples, showing a surface plasmonic resonance (SPR) peak at $420 \mathrm{~nm}$. To prepare polymer composites with reduced energy band gap, different amounts of alumina nanoparticles were incorporated into the CS: AgTf solution. In the present work, the results showed that the reduced silver nanoparticles and their adsorption on wide band gap alumina $\left(\mathrm{Al}_{2} \mathrm{O}_{3}\right)$ particles are an excellent approach for the preparation of polymer composites with small optical band gaps. The optical dielectric loss parameter has been used to determine the band gap experimentally. The physics behind the optical dielectric loss were interpreted from the viewpoint of quantum mechanics. From the quantum-mechanics viewpoint, optical dielectric loss was also found to be a complex equation and required lengthy numerical computation. From the TEM investigation, the adsorption of silver nanoparticles on alumina has been observed. The optical micrograph images showed white spots (silver specks) with different sizes on the surface of the films. The second semicircle in impedance Cole-Cole plots was found and attributed to the silver particles.
\end{abstract}

\section{Introduction}

Ion-conducting polymers, which are solid-state solutions of salts in polymers, are nowadays becoming an active area of material researches $[1,2]$. Polar polymers are able to coordinate with cations of the salt, resulting in the dissolution of the salt. This is due to the presence of functional groups with large sufficient electronegativity $[3,4]$. It is reported that the electrical and optical properties of polymers can be improved to a desired value by incorporating suitable dopant materials $[5,6]$. Since the original work of Weston and Steele [7], nanocomposite polymer electrolytes (NCPEs) have received considerable scientific attention and it has been proven that nanofiller dispersion is an accepted approach to overcome any shortcomings, such as the mechanical strength. Chitin is the second most existing biopolymer in the world, derived from the cell walls of fungi and insect and the exoskeletons of crustaceans [8]. Chitosan is derived from chitin and it has attracted significant attention as a functional, nontoxic, biodegradable biopolymer for a wide application in medicine and in electrochemical devices [9]. The existence of amino and hydroxyl functional groups on CS's backbone structure are the unique properties that separate CS from other biopolymers [10, 11]. Polymers, such as CS, poly(ethylene oxide) (PEO), poly(2-ethyl-2-oxazoline) (POZ), and poly(vinyl pyrrolidone) (PVP), containing polar 
groups have been introduced as a polymer solvent for the silver salts to be dissolved [12]. Earlier works established that lone-pair electrons on the functional groups of polar polymers are responsible for the complexation and reduction of silver ions to silver nanoparticles [13-16]. This phenomenon (i.e., $\mathrm{Ag}^{+} \rightarrow \mathrm{AgO}$ ) limits the application of silver-based ionconducting polymer electrolytes in electrochemical devices $[17,18]$. However, this phenomenon may be beneficial for the preparation of polymer nanocomposites with small optical band gaps [14]. Alumina $\left(\mathrm{Al}_{2} \mathrm{O}_{3}\right)$ has recently received considerable attention in materials science because it is key material in many applications, such as metal-oxide semiconductor devices, dye-sensitized solar cells, and corrosion protection [19]. It is reported that properties of the aluminabased nanocomposites with the transition metals are shown to be improved in comparison to their bulk counterpart. The mechanical and transport properties of alumina have been shown to be improved through the incorporation of silver nanoparticles [20]. The results of the current study reveal that the adsorption of silver nanoparticles on $\mathrm{Al}_{2} \mathrm{O}_{3}$ structure through the host polar polymers produces polymer composites with small optical band gaps.

\section{Materials and Sample Preparation}

Chitosan from crab shells ( $\geq 75 \%$ deacetylated, average molecular weight $1.1 \times 10^{5}$, procured from Sigma), aluminum oxide $\left(\mathrm{Al}_{2} \mathrm{O}_{3}\right.$, size $\left.<50 \mathrm{~nm}\right)$, and silver triflate $\left(\mathrm{AgCF}_{3} \mathrm{SO}_{3}\right)$ were provided by Sigma-Aldrich. Acetic acid with concentration of $1 \%$ was prepared by glacial acetic acid solution and used as a dissolver to prepare the nanocomposite solid polymer electrolytes (SPE). The SPE films were then prepared by the solution cast technique. Here, $1 \mathrm{gm}$ of chitosan (CS) was dissolved in $100 \mathrm{ml}$ of $1 \%$ acetic acid solution. In order to completely dissolve the chitosan powder in the acetic acid solution at room temperature, the mixture was then stirred continuously for several hours by using a magnetic stirrer. Silver triflate (AgTf) with $30 \mathrm{wt}$.\% was then added to the solution. The mixture was further stirred to achieve a homogeneous solution. Here, the color of the solution was changed from colorless to brown, indicating the formation of $\mathrm{AgO}$ in the aqueous solution. Polymer nanocomposites (PNs) were then prepared by dispersing and stirring $\mathrm{Al}_{2} \mathrm{O}_{3}$ in $20 \mathrm{~mL}$ acetic acid solution. The concentrations of $\mathrm{Al}_{2} \mathrm{O}_{3}$ were varied from $1 \%$ to $5 \%$. Next, under constant stirring, the $\mathrm{Al}_{2} \mathrm{O}_{3}$ dispersoids were mixed with CS: $\operatorname{AgTf}(0.7: 0.3)$ solutions. After that, the solutions were cast into various clean and dry Petri dish and they were allowed to be evaporated at room temperature until solvent-free films of NCPE were formed. For further drying, the films were kept in desiccators with blue silica gel desiccant. The samples were coded as PN1, PN2, and PN3 for CS : AgTf incorporated with 1, 3, and 5 wt.\% of $\mathrm{Al}_{2} \mathrm{O}_{3}$ content, respectively.

\section{Characterization Techniques}

The ultraviolet-visible (UV-Vis) spectra, in absorbance mode within the wavelength range of 180-1000 nm, were recorded for the prepared films, using a Jasco V-570, UV-Vis-NIR

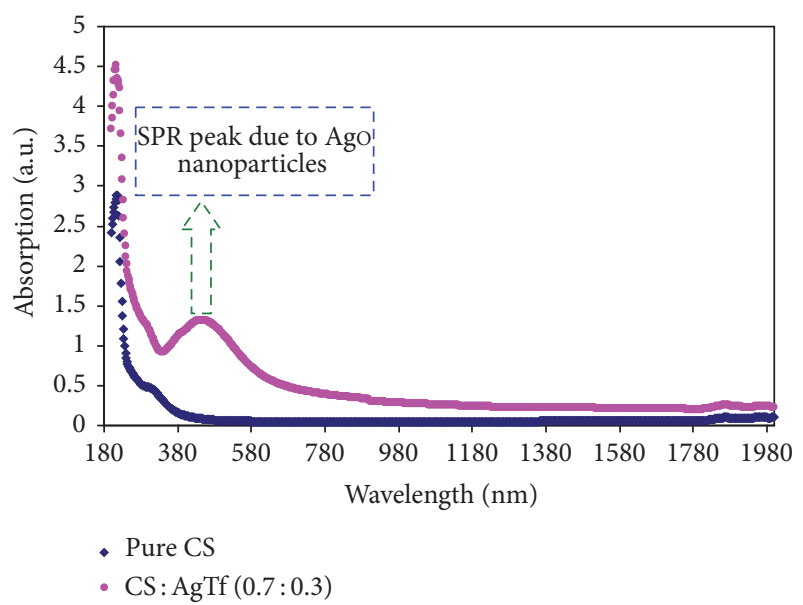

FIGURE 1: The absorption spectra of pure CS and CS : $\operatorname{AgTf}(0.7: 0.3)$ samples.

spectrophotometer (Japan, Jasco SLM-468). An optical microscope (MEIJI, model) was used to realize the nanocomposites films. The images of the surface of the samples at adjusted magnification were taken by a high-quality digital camera attached to the optical microscope and software from Dino-Lite. The impedance of the samples, in the frequency range of $50 \mathrm{~Hz}$ to $1 \mathrm{MHz}$, was also measured by using the HIOKI 3531-Z HiTester. Transmission electron microscopy (TEM) images of the polymer nanocomposites containing $\mathrm{Al}_{2} \mathrm{O}_{3}$ nanoparticles were recorded using a LEO-Libra transmission electron microscope (with accelerating voltage of $120 \mathrm{kV}$ ). The samples for the TEM imaging were prepared by placing a drop of the solution on a carbon-coated copper grid and the solvent was allowed to be dried at room temperature after the removal of excessive solution by a filter paper.

\section{Results and Discussion}

Figure 1 shows the UV-Vis absorption spectra of pure CS and CS : AgTf $(0.7: 0.3)$ samples. From the figure, it is obvious that a surface plasmonic resonance (SPR) peak at $428 \mathrm{~nm}$ is exhibited for the CS : AgTf system, while this peak is absent in the spectrum of pure CS sample. The absorption spectra for the nanocomposite samples were also carried out as shown in Figure 2. It is clear that the optical absorption onset starts at high wavelengths. It can be seen from the figures that all the samples possess the SPR peak at around of $423 \mathrm{~nm}$, which can be related to the existence of silver nanoparticles. In the recent year, extensive investigations have focused on the optical properties of silver nanoparticles. This is due to the strong absorption property of silver nanoparticles in the visible region as a result of the SPR phenomenon [21]. It is well established that the absorption band, which is peaked between $420 \mathrm{~nm}$ and $520 \mathrm{~nm}$, can be related to the silver metal particles formation $[16,18,22]$. Furthermore, the intensity of SPR peak of the composite samples is found to be higher than that of CS : AgTf system. Such intensity increase was found to be directly proportional to the alumina concentration, implying an increasing amount of Ag nanoparticles [17, 18, 


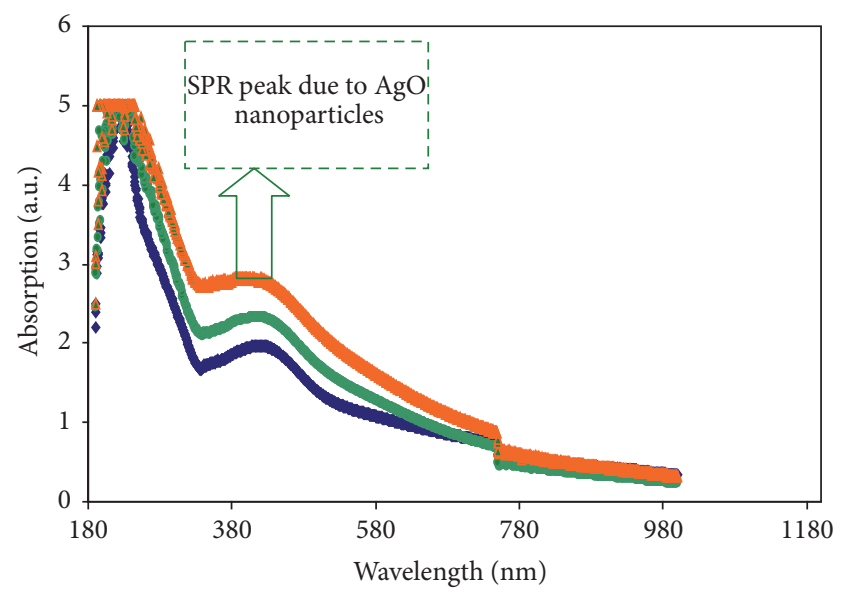

- PN1

- PN2

4 PN3

FIGURE 2: The absorption spectra of nanocomposite samples.

22]. It is important to notice that the SPR peak becomes more broadened with increasing the filler concentration. This may be related to the fact that the reduced silver nanoparticles attach to or enter the alumina structure. In our previous works, similar effect on the broadening of the SPR peaks due to the adsorption silver particles on $\mathrm{TiO}_{2}$ structure has been observed [14]. This phenomenon can be more enlightened by study of band gap.

It is reported that the determination of band gap energy of film materials is considered as one of the important factors in developing their electronic band structure [23]. The estimation of optical band gap from the data of absorption coefficient versus wavelength is actually characterized by Tauc's equation [5]:

$$
\alpha h v=B\left(h v-E_{g}\right)^{n}
$$

where $\alpha, h v, B$, and $E_{g}$ denote the absorption coefficient, the photon energy, the band form parameter, and the optical band gap of the samples, respectively, and $n$ is a constant, which relates to the density of states distribution and determines the type of transition. The values of $n$ are equal to $1 / 2$ and $3 / 2$ for direct allowed and forbidden transitions, respectively. The constant $n$ also takes the values of 2 and 3 for the cases of indirect allowed and forbidden transitions, respectively [24]. Figures 3-5 show the plots of $(\alpha h v)^{1 / n}$ versus photon energy $(h v)$ based on the values of $n$. From these figures, different energy band gaps can be obtained and the dominant type of electronic transition is difficult to be identified. The band gap values were estimated for all the samples as summarized in Table 1 . To precisely specify the types of electronic transition in the samples, optical dielectric loss must be examined. In our previous works $[14,25]$, it is established that the optical dielectric loss is the only parameter that can be used successfully to study the optical band gap and identify the dominant type of electronic transition.

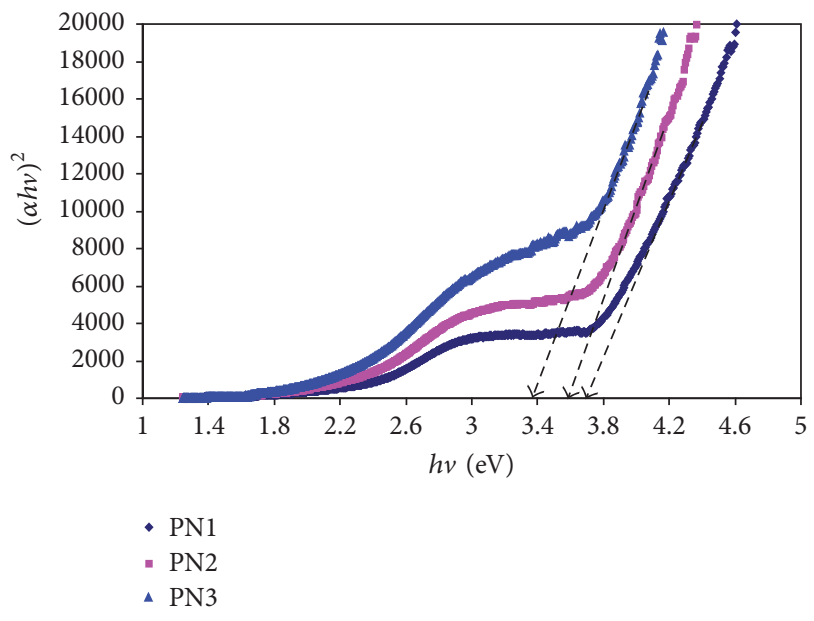

FIGURE 3: The plots of $(\alpha h v)^{2}$ versus $(h v)$ for all nanocomposite samples.

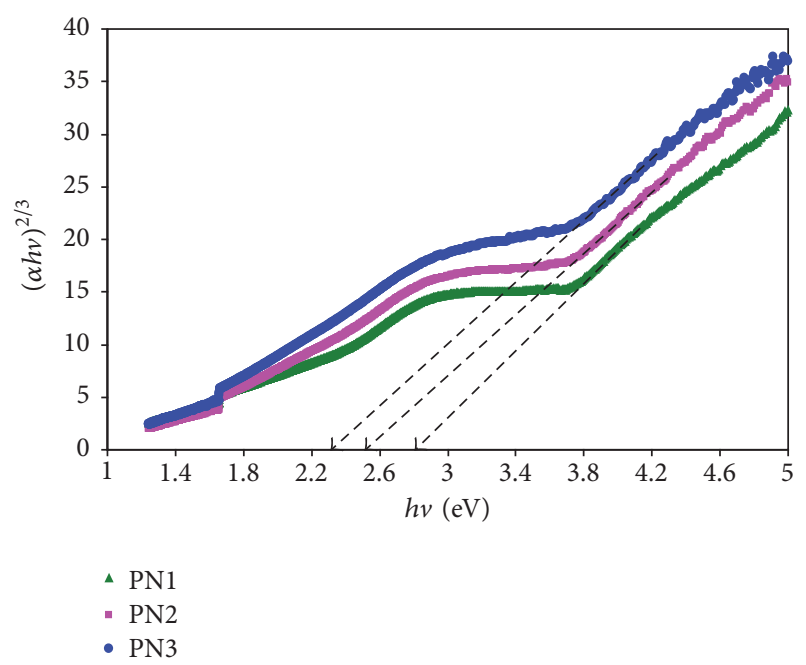

FIgURE 4: The plots of $(\alpha h v)^{2 / 3}$ versus $(h v)$ for all nanocomposite samples.

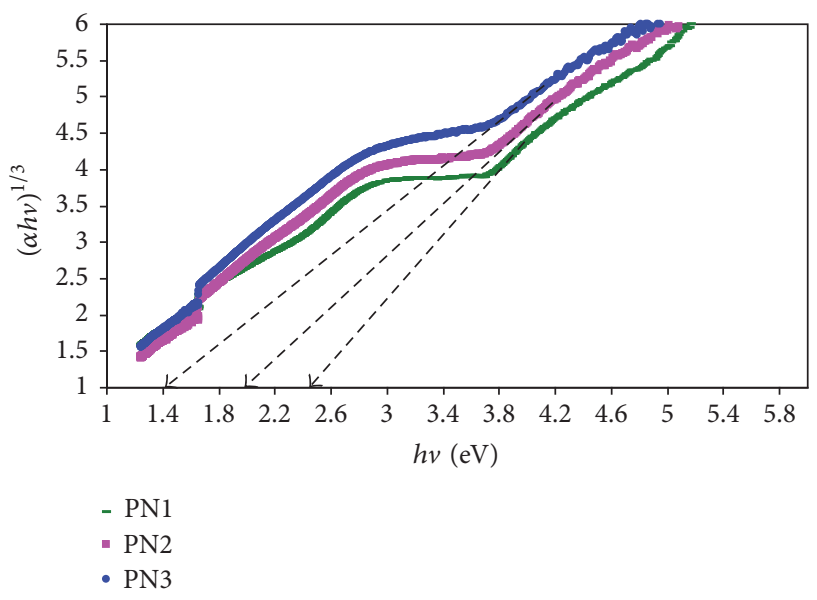

FIGURE 5: The plots of $(\alpha h v)^{1 / 3}$ versus $(h v)$ for all nanocomposite samples. 
TABLE 1: Estimated optical band gap from Tauc's method and optical dielectric loss plot.

\begin{tabular}{lcccc}
\hline $\begin{array}{l}\text { Sample } \\
\text { designation }\end{array}$ & $\begin{array}{c}E_{g}(\mathrm{eV}) \text { from Tauc method } \\
(n=1 / 2)\end{array}$ & $\begin{array}{c}E_{g}(\mathrm{eV}) \text { from Tauc method } \\
(n=3 / 2)\end{array}$ & $\begin{array}{c}E_{g}(\mathrm{eV}) \text { from Tauc method } \\
(n=3)\end{array}$ & $\begin{array}{c}\text { Estimated band gap from } \\
\varepsilon^{\prime \prime}-h v \text { plot }\end{array}$ \\
\hline PN1 & 3.7 & 2.8 & 2.46 & 2.8 \\
PN2 & 3.6 & 2.51 & 1.97 & 2.49 \\
PN3 & 3.36 & 2.3 & 1.4 & 1.4 \\
\hline
\end{tabular}

The optical dielectric function is reported to be closely correlated to the electron-photon interaction, connecting the solid electronic structure to the physical process of interband transition. The imaginary part of the dielectric function mainly identifies the electronic transition from an occupied state to an empty state [26]. The correlation between optical dielectric loss and band structure can be realized from the following equation [27]:

$$
\begin{gathered}
\varepsilon_{2}(\omega)=\frac{C_{1}}{\omega^{2}} \sum_{V \cdot C} \int_{\mathrm{BZ}} d^{3} K \frac{2}{(2 \pi)}\left|e \cdot M_{C V}(K)\right|^{2} \\
\cdot \delta\left(E_{C}(K)-E_{V}(K)-\hbar \omega\right),
\end{gathered}
$$

where $C$ and $V$ denote the conduction band and valence band, respectively, $K$ is the electron wave vector, $\omega$ is the angular frequency, $\mathrm{BZ}$ is the first Brillouin zone, $\mid$ e. $\left.M_{C V}(K)\right|^{2}$ is momentum transition matrix element, $C_{1}$ and $C_{2}$ are constants, and $E_{C}(K)$ and $E_{V}(K)$ denote the intrinsic energy level of the conduction and valence bands, respectively. At the absorption edge, the spectral pattern of $\varepsilon_{i}$ shows a sharp increase and then continues at a constant rate over the high wavelength side and then a peak appears. The peaks of dielectric loss are evidently observed shifting towards lower photon energy with increasing alumina concentration. From the quantum-mechanics (i.e., microscopic) viewpoint, the optical dielectric loss is strongly correlated to the occupied and unoccupied electronic states within a solid. Furthermore, it is microscopically confirmed that the primary peak in the imaginary part of dielectric function is in strong correspondence with the interband transitions [26, 27]. The results of the current work (shown in Figure 6) reveal that the calculated optical dielectric loss $\left(\varepsilon_{i}=2 n K\right)$ against the photon energy can be used to study the optical band gap. Again, from the quantum-mechanics viewpoint, the optical dielectric loss is also established to be correlated with electrons and the density of states near the Fermi energy level. Here, it is also shown that only certain electrons near the Fermi surface can participate to conduct once they absorb photon energies [14, 28]. The type of electronic transition and the optical band gap can be determined by comparison of plots obtained from Tauc's equation to those of optical dielectric loss $[14,25]$. Therefore, the results of this study can reveal the possibility of using measurable macroscopic parameters, such as the optical dielectric loss $\varepsilon_{i}$, to study the band gap structure. This method of determining the band gap of the materials takes little time and is simple to analyze the data and deep knowledge from the viewpoint of physics can still be obtained. The results of this study are found to be in harmony with our previous works $[29,30]$, which reveal that the optical dielectric loss can be a very good approach for the study of band gap and can be considered as an alternative method for Tauc's model. The most important point of our hypothesis for the band gap study is that the optical dielectric loss is sufficient to estimate the optical band gap and Tauc's model is an easy method to specify the type of electronic transition. From the above discussion, it is clear that the optical dielectric loss can effectively be used to study band gap; on the other hand, Tauc's model can be used to determine the type of electronic transition. From the comparison of Figure 6 with plots obtained from Tauc's method (Figures $3-5)$, it can be observed that the optical transition in PN1 and PN2 systems is forbidden direct transition type (i.e., $n=3 / 2$ ), while PN3 system follows the forbidden indirect transition type (i.e., $n=3$ ). It is clear that the sample incorporated with 5 wt.\% of alumina exhibits smallest band gap of $1.4 \mathrm{eV}$. Earlier studies revealed that the wide optical band gap of materials can be significantly tuned by incorporating nanoparticles $[14,19,31]$. Canulescu et al. successfully reduced the optical band gap of $\mathrm{Al}_{2} \mathrm{O}_{3}$ from $7.3 \mathrm{eV}$ to $6.2 \mathrm{eV}$ by incorporating $20 \mathrm{wt} . \%$ of titanium (Ti) atoms to the structure [19]. Similarly, an interesting reduction in the alumina band gap was also observed by Wang et al. [31]. In their studies, energy band gap of $2.82 \mathrm{eV}$ has been achieved for the incorporated alumina with the AgI nanoparticle. Such reduction was attributed to the presence of unoccupied states within the band gap of $\mathrm{Al}_{2} \mathrm{O}_{3}$. Compared to literatures [19, 31], the band gap of semiconductors and insulators can be further reduced in polymer composites. This is related to the fact that the conduction band of the adsorbed Ag metal particles on alumina structure can coat the valence band and the part of forbidden band under the Fermi energy level. Consequently, a metal-semiconductor interface layer may build up due to the wave function tail. These states are often called metalinduced gap states (MIGS) [14]. Here, the results of this work show that the reduction of silver ions to silver nanoparticles in polar polymers in addition to their adsorption on wide band gap materials, such as $\mathrm{Al}_{2} \mathrm{O}_{3}$, is an excellent method for developing the small optical band gap polymer composites. The measurement method of TEM is being recognized as the most accurate method to analyze the internal structure and view the defect structure by direct visualization of thin films [11]. Figure 7 shows the TEM image of the $\mathrm{Al}_{2} \mathrm{O}_{3}$ particles dispersed in chitosan. Here, one can see in Figure 7 that the alumina particles are dispersed with distinguishable distances. The TEM image for CS : AgTf system incorporated with $5 \mathrm{wt} . \%$ of alumina particles was also taken as shown in Figure 8. The figure reveals that most of alumina particles are covered by dark clouds of AgO nanoparticles. Such AgO adsorptions are believed to be responsible for the shrinkage 


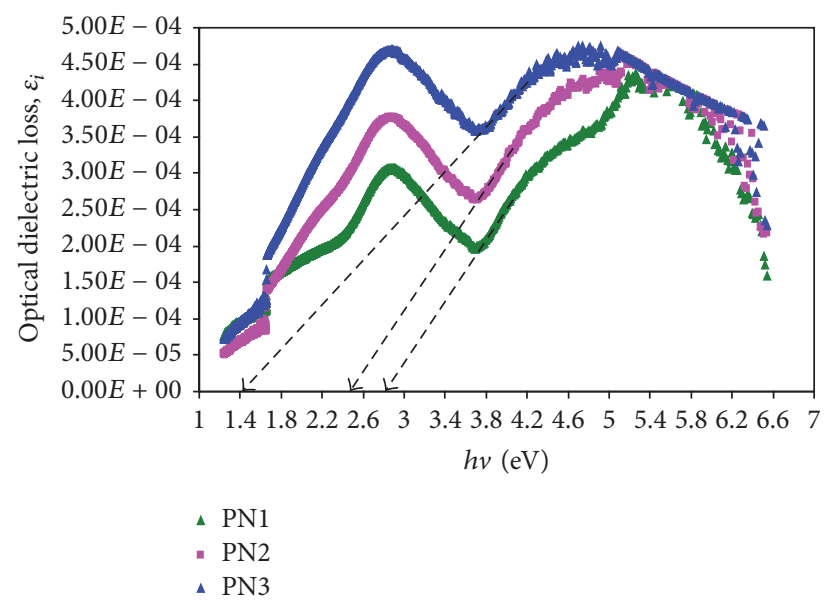

Figure 6: The plots of optical dielectric loss versus photon energy $(h v)$ for all the samples.

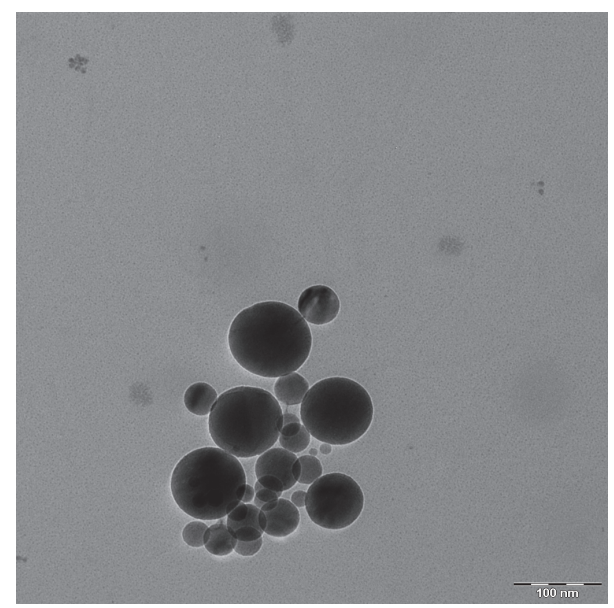

FIgURE 7: TEM image for the dispersion of $5 \mathrm{wt} . \% \mathrm{Al}_{2} \mathrm{O}_{3}$ particles in chitosan.

of the band gap. From Figure 6, the large amount of silver particles appears as a dark color spot $[16,22]$. Similarly, TEM method was also used by Vimala et al. to observe the formation and distribution of silver nanoparticles in chitosan: $\mathrm{AgNO}_{3}$ nanocomposite [32].

The surface morphological study may provide more information about the metallic silver particles formation. Figure 9 shows the optical micrographs of all samples studied in this work. From the surface scan of the films, different sizes of metallic silver particles appearing as white spots were observed. As reported by Sekhon et al., these white spots are attributed to the leakage of metallic silver particles [33]. Such reduction occurs since the polar polymer solvents can act as reducing agents on the cations of the silver salts [34]. From Figure 9, one can see that the number of white spots has been increased with increasing alumina concentration. These findings reveal that the alumina nanoparticles can prevent the reduction of silver ion at low salt concentration ( $\leq 10 \mathrm{wt} . \%$ AgTf) $[9,18]$, while at high salt concentration (30 wt.\% AgTf) the alumina filler assists more silver salt

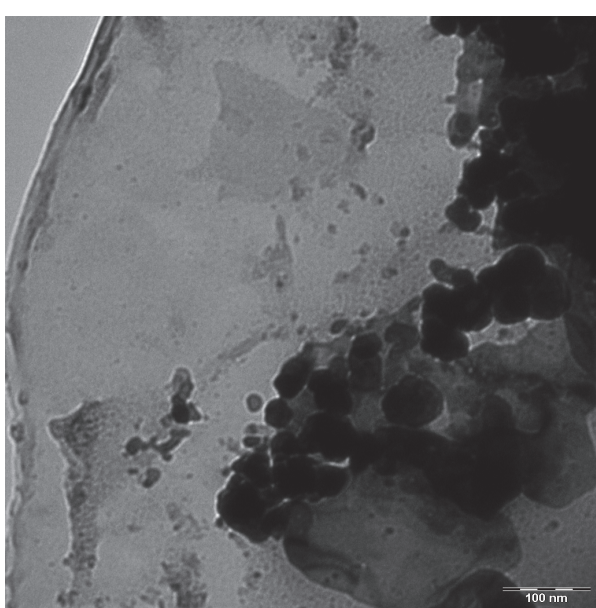

FIGURE 8: TEM image for CS: AgTf $(0.7: 0.3)$ incorporated with 5 wt. $\%$ of $\mathrm{Al}_{2} \mathrm{O}_{3}$ particles (PN3).

reduction as observed in Figure 9. It is well reported that, at low filler concentrations, most of the Lewis acid sites of alumina nanoparticles interact with anion of the salt, leading the interaction intensity to be decreased between the silver cation and its anion and thus a higher ionic conductivity [ $[$, $18,35]$. The study of impedance plots may be useful to support this interpretation. However, at high filler concentrations, aggregation of the filler is expected to occur, due to the self-segregation of the nanoparticles, which arises from the hydrogen-bonding interactions among the $\mathrm{OH}$ groups on the filler surfaces $[11,35]$. In this case, most of the silver ions may possess a reduction through the polymer polar groups and, thus, an enhancement in the SPR peak. As a result of that, more silver particles may adsorb on the alumina particles, leading the band gap to be significantly decreased, as observed in Figure 5. The produced silver nanoparticles may act as grain boundaries for ion transport [22]. The reduction of silver ions has two effects. First, the number of ions related to the conductivity reduces, which is considered as a side effect in the application viewpoint of electrochemical devices. Second, the adsorption of silver nanoparticles on alumina particles shrinks the optical band gap which is important for photonics application.

The interparticle interaction, such as grain and grain boundary effects, can be determined with the aid of complex impedance formalism [36]. To investigate the contribution owing to different effects, the impedance Cole-Cole plot has been examined for different alumina concentrations. Figure 10 shows the impedance Cole-Cole plots measured for the composite samples. Two different phenomena can be recognized from the impedance spectra measured between the high and low frequency regions. The semicircle obtained at the higher frequency region can be attributed to the ion transport through the electrolyte, such as ionic conductivity [37]. On the other hand, the points in the impedance plots completing the second semicircle can be attributed to the presence of metallic silver particles, which act as grain boundaries [22]. In real solid electrolytes, the highfrequency dispersion characterizes the bulk material property 

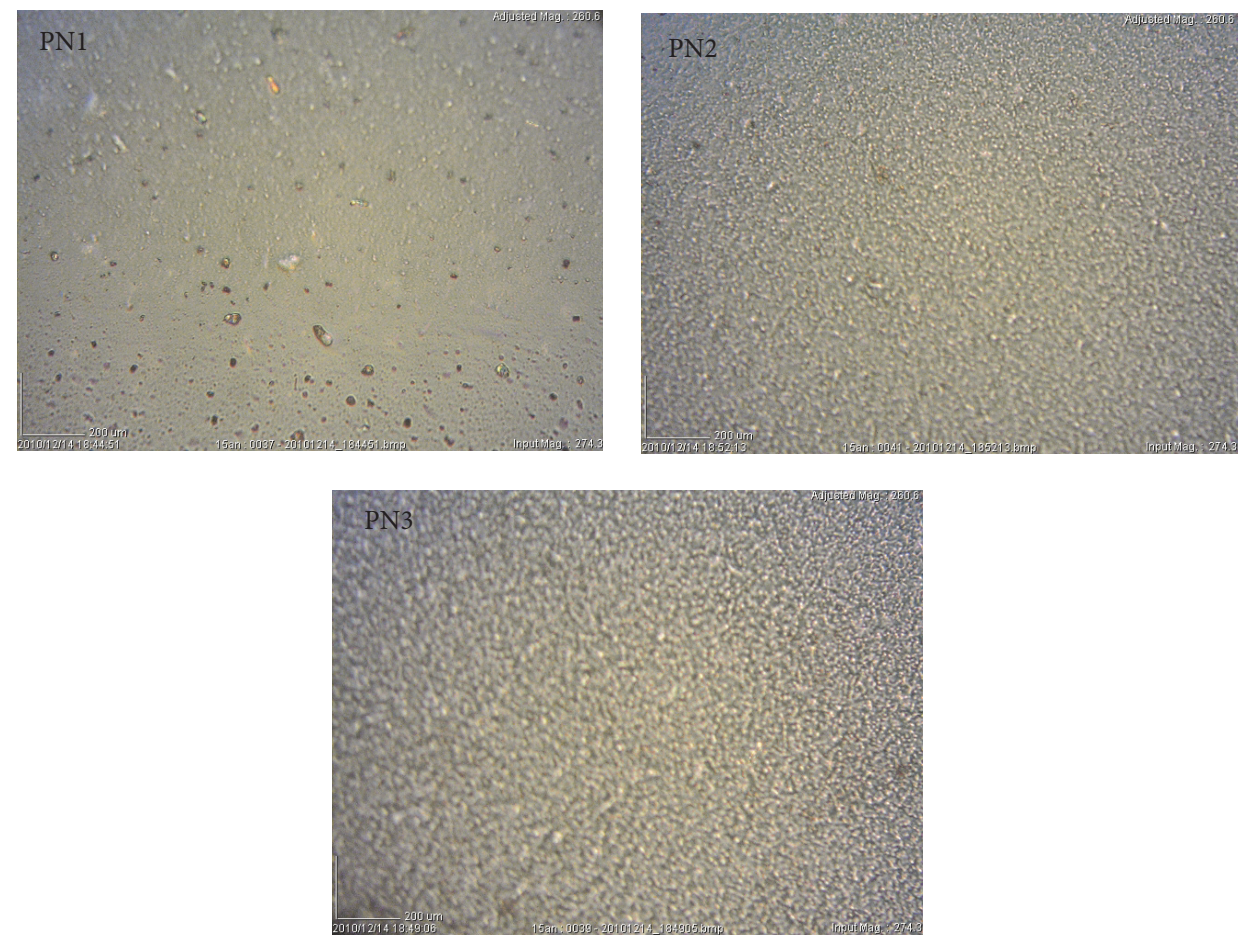

FIGURE 9: Surface images for all nanocomposite films.

[38]. Interfacial properties, which dominate the spectra at low frequencies and high temperature, are attributed to electrical double layer capacitances (EDLC) $[16,37]$. At the low frequencies, the little data points are assigned to the EDLC phenomenon as a consequence of ion accumulation at the electrode/electrolyte interface [16]. It can be seen that the diameter of impedances at high filler concentration is increased because of the grain boundaries. This indicates that more silver ions are reduced to silver nanoparticles. It is important to mention here that the results found from the optical absorption measurements (SPR peaks) and optical micrograph images support the obtained results from the impedance measurements. Moreover, the increase of diameter of semicircles which is attributed to the formation of huge amount of silver particles confirms the achieved results of energy band gaps. It is well known that the differences in electrical property of materials originate from the band structures. Therefore, understanding the band gap is tremendously important [29]. The bulk resistivity increases when a large amount of silver ions reduced to silver particles, as depicted in Figure 10. On the other hand, the energy band gap has been decreased (see Figure 6) due to the adsorption of large amount of silver particles on alumina structure. The results of the present work are essentially a great contribution to the field of polymer electrolytes and polymer composites. To the best of our knowledge, this is the first work that interprets the electrical and optical properties based on structure properties relationships. Other than the above findings, the Cole-Cole plots can also provide information about the nature of dielectric relaxation. For a pure Debye-type monodispersive process, it is possible to achieve semicircular arcs centered on the $Z_{r}$-axis [36]. It is obvious that the plots of Argand show incomplete semicircular arc with a diameter below the real impedance axis. The existence of the semicircle with its center below the real axis indicates that ions have different relaxation times $[22,39,40]$.

\section{Conclusions}

Silver nanoparticles inside the chitosan polymer have been synthesized by in situ method. The surface plasmonic resonance (SPR) peaks at $420 \mathrm{~nm}$ have been observed. Different amounts of alumina nanoparticles were incorporated into chitosan : silver triflate (CS : AgTf) system. The SPR peaks for such incorporated samples have been found to be broadened. The adsorption of silver particles on alumina was also developed. Furthermore, the onset of absorption has been observed at high wavelengths for the incorporated samples with alumina contents. The results achieved in this work show that the reduced silver nanoparticles and their adsorption upon wide band gap particles, such as $\mathrm{Al}_{2} \mathrm{O}_{3}$, represent an excellent technique to prepare the polymer composites with small optical band gaps. The optical band gap has been studied in detail by two distinct methods. Optical dielectric loss parameter $\left(\varepsilon_{i}\right)$ associated with the electron transition from the occupied states to unoccupied states has been used to determine the band gap. From the quantum-mechanics viewpoint, the optical dielectric loss as an interesting parameter for the band gap study has been interpreted. Moreover, from the comparison of Tauc's plots and optical dielectric loss plot, the types of electron transition were identified. The formation of silver particles and their adsorption on alumina have been clearly observed from the transmission 

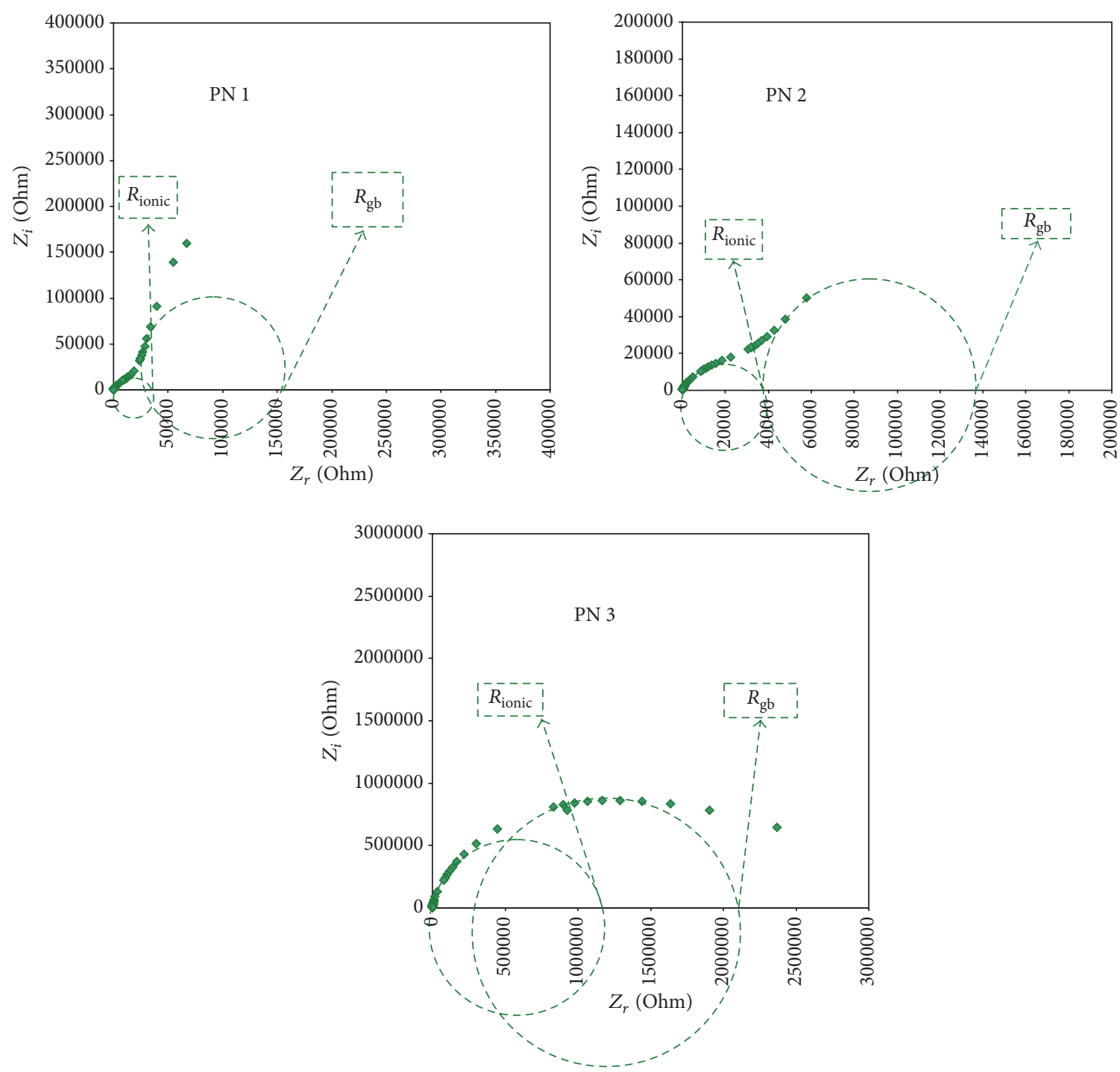

FIgure 10: Cole-Cole ( $\mathrm{Zi}$ versus $\mathrm{Zr}$ ) plots for all the nanocomposite samples.

electron microscopy (TEM) images. In addition to the TEM analysis, optical micrograph for the surface morphology of the films has been studied. The images revealed white spots (silver specks) with different sizes on the surface of the films. To investigate the interparticle interaction, such as grain and grain boundary effects, the impedance Cole-Cole plot has been examined for different alumina concentrations. The second semicircle in Cole-Cole plots was found and attributed to the silver particles. The relaxation process has also been found to be of non-Debye type.

\section{Conflicts of Interest}

The authors declare that there are no conflicts of interest regarding the publication of this article.

\section{Acknowledgments}

The authors gratefully acknowledge the financial support for this study from Ministry of Higher Education and Scientific
Research, Kurdistan Regional Government, Department of Physics, College of Science, University of Sulaimani, Sulaimani, and Development Center for Research and Training (DCRT), University of Human Development.

\section{References}

[1] L. Liu, X. Feng, and A. Chakma, "Unusual behavior of poly(ethylene oxide)/AgBF4 polymer electrolyte membranes for olefinparaffin separation," Separation and Purification Technology, vol. 38, no. 3, pp. 255-263, 2004.

[2] Shujahadeen B. Aziz and Zul Hazrin Z. Abidin, "Electrical Conduction Mechanism in Solid Polymer Electrolytes: New Concepts to Arrhenius Equation," Journal of Soft Matter, vol. 2013, Article ID 323868, 8 pages, 2013.

[3] J. H. Kim, H. Won, and Y. S. Kang, "Olefin-induced dissolution of silver salts physically dispersed in inert polymers and their application to olefin/paraffin separation," Journal of Membrane Science, vol. 241, pp. 403-407, 2004. 
[4] S. B. Aziz, " $\mathrm{Li}^{+}$ion conduction mechanism in poly ( $\varepsilon$-caprolactone)-based polymer electrolyte," Iranian Polymer Journal, vol. 22, no. 12, pp. 877-883, 2013.

[5] S. B. Aziz, H. M. Ahmed, A. M. Hussein, A. B. Fathulla, R. M. Wsw, and R. T. Hussein, "Tuning the absorption of ultraviolet spectra and optical parameters of aluminum doped PVA based solid polymer composites," Journal of Materials Science: Materials in Electronics, vol. 26, no. 10, pp. 8022-8028, 2015.

[6] O. Gh. Abdullah, S. B. Aziz, K. M. Omar, and Y. M. Salih, "Reducing the optical band gap of polyvinyl alcohol (PVA) based nanocomposite," vol. 26, pp. 5303-5309, 2015, Journal of Materials Science: Materials in Electronics.

[7] S. B. Aziz and Z. H. Z. Abidin, "Ion-transport study in nanocomposite solid polymer electrolytes based on chitosan: Electrical and dielectric analysis," Journal of Applied Polymer Science, vol. 132, no. 15, Article ID 41774, 2015.

[8] V. K. Mourya and N. N. Inamdar, "Chitosan-modifications and applications: opportunities galore," Reactive \& Functional Polymers, vol. 68, pp. 1013-1051, 2008.

[9] S. B. Aziz, M. A. Rasheed, and Z. H. Z. Abidin, "Optical and Electrical Characteristics of Silver Ion Conducting Nanocomposite Solid Polymer Electrolytes Based on Chitosan," Journal of Electronic Materials, vol. 46, no. 10, pp. 6119-6130, 2017.

[10] S. B. Aziz, "Occurrence of electrical percolation threshold and observation of phase transition in chitosan ${ }_{(1-x)}: \operatorname{AgI}_{x}(0.05 \leq$ $x \leq 0.2$ )-based ion-conducting solid polymer composites," Applied Physics A: Materials Science \& Processing, vol. 122, 706 pages, 2016.

[11] Shujahadeen B. Aziz, "Role of Dielectric Constant on Ion Transport: Reformulated Arrhenius Equation," Advances in Materials Science and Engineering, vol. 2016, Article ID 2527013, 11 pages, 2016.

[12] S. W. Kang, J. H. Kim, J. Won, K. Char, and Y. S. Kang, "Effect of amino acids in polymer/silver salt complex membranes on facilitated olefin transport," Journal of Membrane Science, vol. 248, no. 1-2, pp. 201-206, 2005.

[13] S. B. Aziz, O. Gh. Abdullah, D. R. Saber, M. A. Rasheed, and H. M. Ahmed, "Investigation of Metallic Silver Nanoparticles through UV-Vis and Optical Micrograph Techniques," International Journal of Electrochemical Science, vol. 12, pp. 363-373, 2017.

[14] S. B. Aziz, O. Gh. Abdullah, and M. A. Rasheed, "A novel polymer composite with a small optical band gap: new approaches for photonics and optoelectronics," Journal of Applied Polymer Science, vol. 134, no. 21, Article ID 44847, 2017.

[15] D. Wei, W. Sun, W. Qian, Y. Ye, and X. Ma, "The synthesis of chitosan-based silver nanoparticles and their antibacterial activity," Carbohydrate Research, vol. 344, no. 17, pp. 2375-2382, 2009.

[16] S. B. Aziz, Z. H. Z. Abidin, and A. K. Arof, "Influence of silver ion reduction on electrical modulus parameters of solid polymer electrolyte based on chitosansilver triflate electrolyte membrane," eXPRESS Polymer Letters, vol. 4, no. 5, pp. 300-310, 2010.

[17] S. B. Aziz and Z. H. Z. Abidin, "Innovative method to avoid the reduction of silver ions to silver nanoparticles $\left(\mathrm{Ag}^{+} \rightarrow \mathrm{Ag}^{\circ}\right)$ in silver ion conducting based polymer electrolytes," Materials Chemistry and Physics, vol. 144, pp. 280-286, 2014.

[18] S. B. Aziz, Z. H. Z. Abidin, and M. F. Z. Kadir, "Innovative method to avoid the reduction of silver ions to silver nanoparticles in silver ion conducting based polymer electrolytes," Physica Scripta, vol. 90, Article ID 035808, p. 9, 2015.
[19] S. Canulescu, K. Rechendorff, C. N. Borca et al., "Band gap structure modification of amorphous anodic $\mathrm{Al}$ oxide film by Ti-alloying," Applied Physics Letters, vol. 104, no. 12, Article ID 121910, 2014.

[20] A. A. Anappara, S. K. Ghosh, P. R. S. Warrier, K. G. K. Warrier, and W. Wunderlich, "Impedance spectral studies of sol-gel alumina-silver nanocomposites," Acta Materialia, vol. 51, no. 12, pp. 3511-3519, 2003.

[21] J. H. Kim, C. K. Kim, J. Won, and Y. S. Kang, "Role of anions for the reduction behavior of silver ions in polymer/silver salt complex membranes," Journal of Membrane Science, vol. 250, no. 1-2, pp. 207-214, 2005.

[22] S. B. Aziz, Z. H. Z. Abidin, and A. K. Arof, "Effect of silver nanoparticles on the DC conductivity in chitosansilver triflate polymer electrolyte," Physica B: Condensed Matter, vol. 405, no. 21, pp. 4429-4433, 2010.

[23] S. B. Aziz, R. T. Abdulwahid, H. A. Rsaul, and H. M. Ahmed, "In situ synthesis of CuS nanoparticle with a distinguishable SPR peak in NIR region," Journal of Materials Science: Materials in Electronics, vol. 27, no. 5, pp. 4163-4171, 2016.

[24] R. T. Abdulwahid, O. G. Abdullah, S. B. Aziz, S. A. Hussein, F. F. Muhammad, and M. Y. Yahya, "The study of structural and optical properties of PVA:PbO2 based solid polymer nanocomposites," Journal of Materials Science: Materials in Electronics, vol. 27, no. 11, pp. 12112-12118, 2016.

[25] S. B. Aziz, O. G. Abdullah, A. M. Hussein et al., "Optical properties of pure and doped PVA:PEO based solid polymer blend electrolytes: two methods for band gap study," Journal of Materials Science: Materials in Electronics, vol. 28, no. 10, pp. 7473-7479, 2017.

[26] L. Yu, D. Li, S. Zhao, G. Li, and K. Yang, "First Principles Study on Electronic Structure and Optical Properties of Ternary GaAs:Bi Alloy," Materials, vol. 5, no. 12, pp. 2486-2497, 2012.

[27] Z. E. Biskeri, H. Rached, M. Bouchear, D. Rached, and M. S. Aida, "A comparative study of structural stability and mechanical and optical properties of fluorapatite $\left(\mathrm{ca}_{5}\left(\mathrm{po}_{4}\right)_{3} \mathrm{f}\right)$ and lithium disilicate $\left(\mathrm{li}_{2} \mathrm{Si}_{2} \mathrm{O}_{5}\right)$ components forming dental glassceramics: first principles study," Journal of Electronic Materials, vol. 45, no. 10, pp. 5082-5083, 2016.

[28] M. Park, X. Zhang, M. Chung, G. B. Less, and A. M. Sastry, "A review of conduction phenomena in Li-ion batteries," Journal of Power Sources, vol. 195, no. 24, pp. 7904-7929, 2010.

[29] S. B. Aziz, M. A. Rasheed, A. M. Hussein, and H. M. Ahmed, "Fabrication of polymer blend composites based on [PVAPVP] $]_{(1-x)}:\left(\operatorname{Ag}_{2} \mathrm{~S}\right)_{x}(0.01 \leq x \leq 0.03)$ with small optical band gaps: Structural and optical properties," Materials Science in Semiconductor Processing, vol. 71, pp. 197-203, 2017.

[30] S. B. Aziz, M. A. Rasheed, and H. M. Ahmed, "Synthesis of polymer nanocomposites based on [Methyl Cellulose] $]_{(1-x)}:(\mathrm{CuS})_{x}$ $(0.02 \mathrm{M} \leq x \leq 0.08 \mathrm{M})$ with desired optical band gaps," Polymers, vol. 9 , no. 6, 2017.

[31] Y. Wang, J. Mo, W. Cai, L. Yao, and J. Zhang, "Synthesis of nano-AgI arrays and their optical properties," Journal Materials Research, vol. 16, no. 4, pp. 990-992, 2001.

[32] K. Vimala, Y. M. Mohan, K. S. Sivudu et al., "Fabrication of porous chitosan films impregnated with silver nanoparticles: a facile approach for superior antibacterial application," Colloids and Surfaces B: Biointerfaces, vol. 76, no. 1, pp. 248-258, 2010.

[33] S. S. Sekhon, G. Singh, S. A. Agnihotry, and S. Chandra, "Solid polymer electrolytes based on polyethylene oxide-silver thiocyanate," Solid State Ionics, vol. 80, no. 1-2, pp. 37-44, 1995. 
[34] S. W. Kang, J. H. Kim, K. S. Oh et al., "Highly stabilized silver polymer electrolytes and their application to facilitated olefin transport membranes," Journal of Membrane Science, vol. 236, no. 1-2, pp. 163-169, 2004.

[35] S. W. Kang, J. H. Kim, K. Char, J. Won, and Y. S. Kang, "Nanocomposite silver polymer electrolytes as facilitated olefin transport membranes," Journal of Membrane Science, vol. 285, no. 1-2, pp. 102-107, 2006.

[36] C. K. Suman, K. Prasad, and R. N. P. Choudhary, "Impedance analysis of Pb2Sb3LaTi5O18 ceramic," Materials Chemistry and Physics, vol. 97, no. 2-3, pp. 425-430, 2006.

[37] M. Marzantowicz, J. R. Dygas, and F. Krok, "Impedance of interface between PEO:LiTFSI polymer electrolyte and blocking electrodes," Electrochimica Acta, vol. 53, no. 25, pp. 74177425, 2008.

[38] S. Austin Suthanthiraraj, D. Joice Sheeba, and B. Joseph Paul, "Impact of ethylene carbonate on ion transport characteristics of PVdF-AgCF3SO3 polymer electrolyte system," Materials Research Bulletin, vol. 44, no. 7, pp. 1534-1539, 2009.

[39] S. B. Aziz, "Study of electrical percolation phenomenon from the dielectric and electric modulus analysis," Bulletin of Materials Science, vol. 38, no. 6, pp. 1597-1602, 2015.

[40] S. B. Aziz, R. M. Abdullah, M. A. Rasheed, and H. M. Ahmed, "Role of ion dissociation on dc conductivity and silver nanoparticle formation in pva:agnt based polymer electrolytes: deep insights to ion transport mechanism," Polymers, vol. 9, no. 8, p. 338, 2017. 

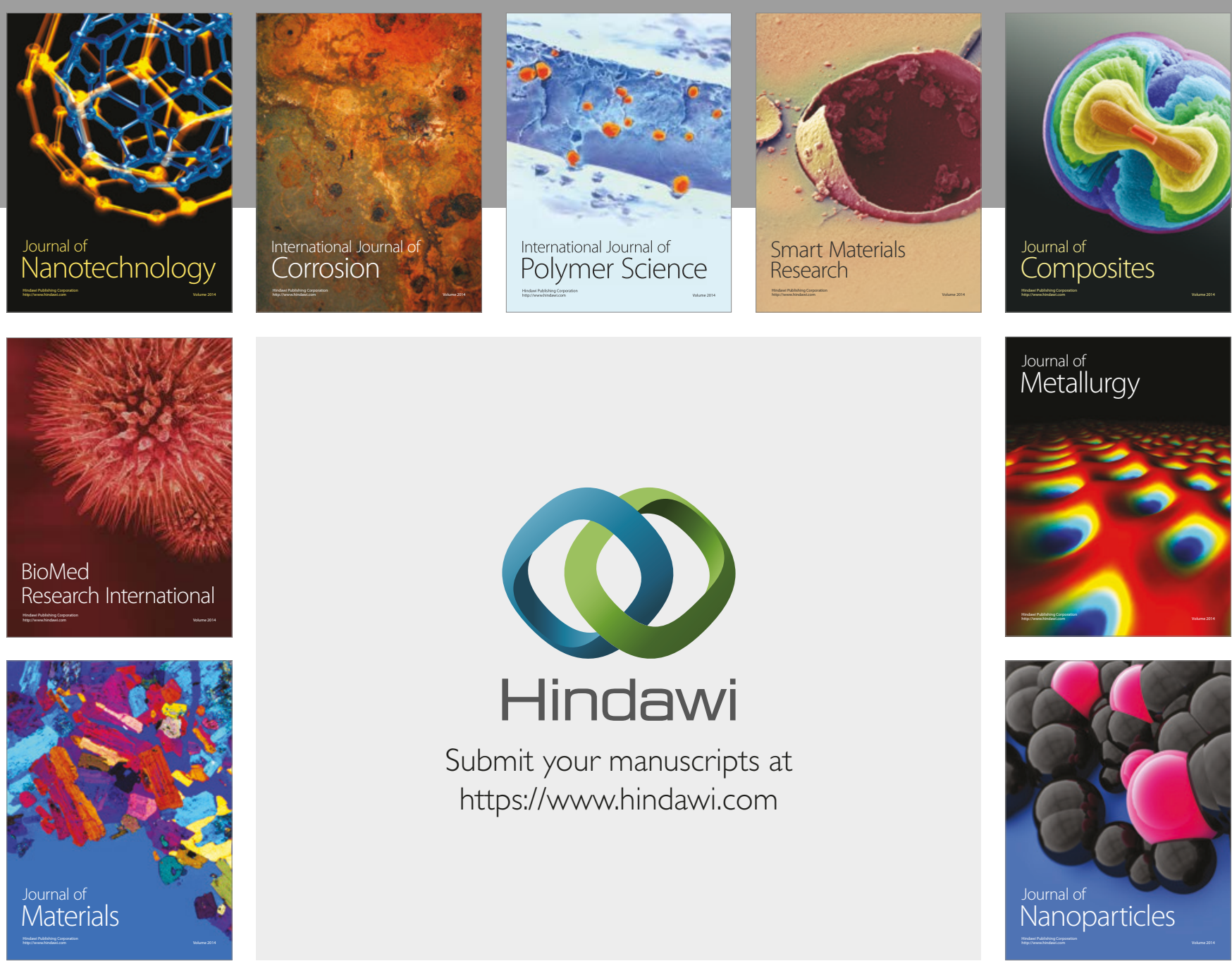

\section{Hindawi}

Submit your manuscripts at

https://www.hindawi.com
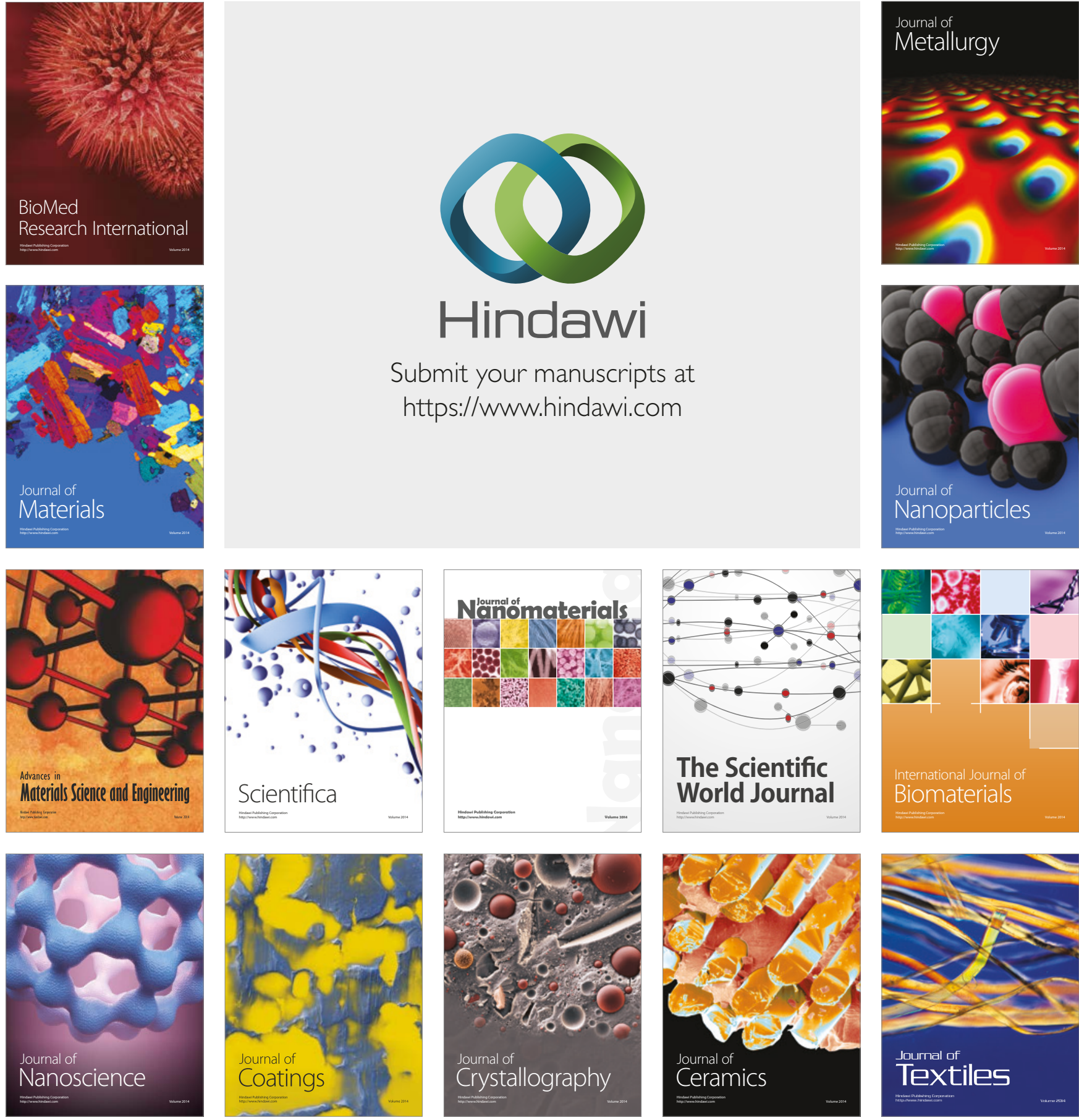

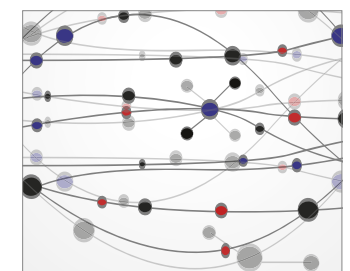

The Scientific World Journal
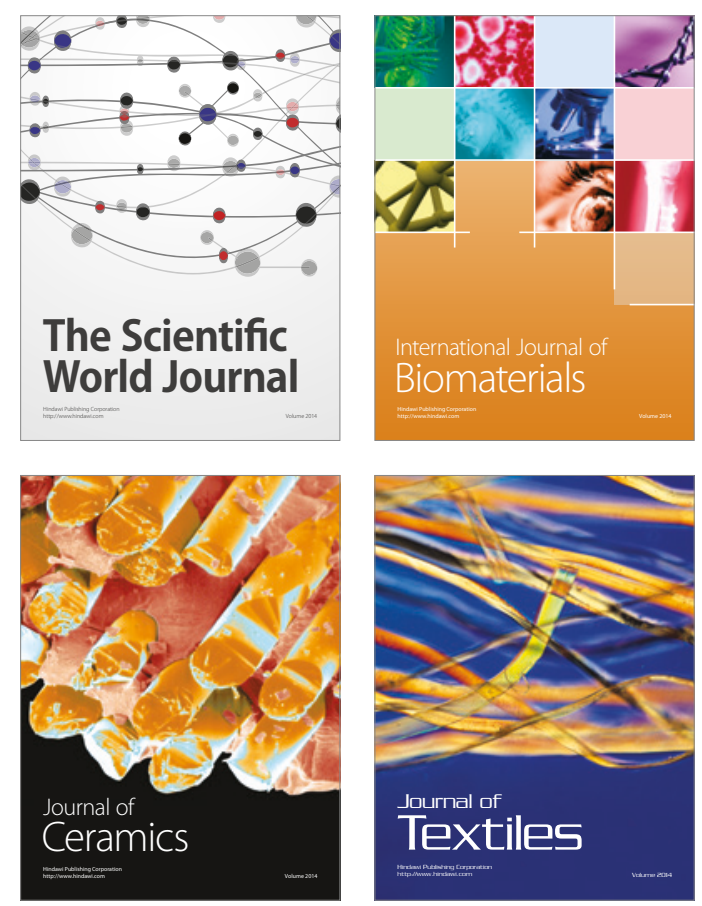